\title{
The JAC Airborne EM system: AEM-05
}

H. Leväniemi ${ }^{(a)}$, D. Beamish ${ }^{(b)}$, H. Hautaniemi ${ }^{(a)}$, M. Kurimo ${ }^{(a)}$, I. Suppala ${ }^{(a)}$, J. Vironmäki ${ }^{(a)}$, R.J. Cuss ${ }^{(b)}$, M. Lahti ${ }^{(b)}$, E.Tartaras $^{(b)}$

Corresponding author:

David Beamish

British Geological Survey, Keyworth, Nottingham, NG12 5GG, UK

Email: dbe@,bgs.ac.uk.

Tel: +44(0)1159363432

Fax: $+44(0) 1159363261$

(a) Geological Survey of Finland, PO Box 96, FI-02151 Espoo, Finland.

(b) British Geological Survey, Keyworth, Nottingham, NG12 5GG, UK.

For submission to the Journal of Applied Geophysics (special issue airborne geophysics).

Revised version 1.0 May 2007.

Keywords:

Airborne geophysics, Electromagnetic methods, instrumentation, software, applications 


\begin{abstract}
This paper describes the airborne electromagnetic (AEM) system operated by the Joint Airborne geoscience Capability (JAC), a partnership between the Finnish and British Geological Surveys. The system is a component of a 3-in-1, fixed-wing facility acquiring magnetic gradiometer and full spectrum radiometric data alongside the wing-tip, frequency-domain AEM measurements. The AEM system has recently (2005) been upgraded from 2 to 4 frequencies and now provides a bandwidth from $900 \mathrm{~Hz}$ to $25 \mathrm{kHz}$. The fixed-wing configuration of 4 dual vertical coplanar coils, offers a high signal/noise by virtue of the wingspan separation of the sensors. This unique configuration allows 3-in-1 surveys to be successfully performed at a variety of survey elevations when regulatory conditions are imposed. Its deployment on a twin-engine aircraft also permits low altitude surveying in countries, such as the UK, where this is a requirement.

The development of the new AEM-05 system has been incremental and its history can be traced back over five decades. The AEM data acquired in the Finnish National Mapping project, and across northern Europe, have been used extensively in mineral exploration. More recent projects have investigated the application of the data to environmental, hydrogeological and land quality issues. These studies have been enhanced by reducing the flight line separation from $200 \mathrm{~m}$ (the national highresolution scale) to $50 \mathrm{~m}$.

Our surveys also increasingly involve the application of AEM across populated areas often with extensive infrastructure. Additional secondary instrumentation has been introduced to provide an increased understanding of the data and the AEM responses observed. The secondary systems include an accurate, high sampling rate laser altimeter, a downward-looking digital camera to record the flight path, a $50 / 60 \mathrm{~Hz}$ power line monitor and a GPS gyroscope. The paper is intended as an overview and provides descriptions of the new AEM system, the secondary systems now employed and some of the software used to provide accurate and levelled AEM data. Recent applications of the system are reviewed and the challenging nature of the new subsurface information being revealed is demonstrated.
\end{abstract}




\section{Introduction: Historical Development and Rationale}

The new Joint Airborne geoscience Capability 3-in-1 system and especially its AEM concept are based on the pioneering work carried out by the Geological Survey of Finland (GTK) over the last 55 years (Peltoniemi, 2005). Know-how and experience have accumulated over those years by carrying out continuous surveys in Finland (the Finnish National Mapping Project) and also on specific projects in Europe and Africa. In addition to its long-established track record in airborne geophysics, GTK sees a continuing need to develop airborne geoscience to address a range of new applications. At the same time, the British Geological Survey (BGS) plans to acquire a new generation of high-resolution airborne data across the UK, to define the properties of the shallow subsurface in relation to sustainable development and environmental protection. The rationale behind developing a joint capability is to share the cost of ownership, maximise the utilisation of the facility, share the cost of technical R\&D and maximise collaborative scientific opportunities. An additional aim is to promote the maintenance and wider development of scientific know-how in airborne geophysics within the European Community.

The joint facility was based initially on GTK's existing 'Three-in-One' fixed wing technology comprising a dual frequency electromagnetic system designed and built by GTK, a multi-channel gamma spectrometer and a magnetic gradiometer. BGS purchased the deHavilland Twin Otter aircraft, previously leased by GTK, and assigned it exclusively for use by the JAC. The scientific operators are provided by GTK and BGS, and the aircrew and maintenance are provided by the Finnish Aviation Academy (FAA) under contract to the JAC.

The two-frequency system has been adequate for the Finnish National Mapping Project and has also proved to be useful for other more detailed, specific surveys. However, when the JAC between BGS and GTK was established, further AEM development work was considered essential. The need for a more sensitive AEM system stems from a recent requirement to increase the vertical resolution and to provide effective data for 2D/3D modelling and inversion. Such quantitative uses of the data are required to support protection of the environment and sustainable landuse management studies. These are programmes that play an increasingly important role within geological organizations such as BGS and GTK.

In addition to the AEM development work, the JAC Research and Development project also included additional survey equipment, such as a high resolution laser altimeter with a high sampling rate and a digital camera to record images of the ground path. A 50/60 Hz power line monitor (PLM) was also installed in the nose cone of the aircraft. The items are particularly useful for surveys over populated areas where deculturing of the data is a potential issue.

Increasing survey volumes also make demands on survey quality and efficiency. Over the last twenty years, the annual survey kilometres flown by GTK/JAC have typically been in the range 60,000 - 80,000 kilometres, with the trend increasing (Hautaniemi et al., 2005). During 2006, total survey kilometres amounted to approximately 85,000 with an accumulated total airborne survey time of almost 700 hours. Survey volumes 
at this level lead to a requirement for robust hardware and efficient software as discussed below.

\section{Development and Properties of the 4-frequency AEM-05 system}

The previous GTK AEM system (AEM-95) had two frequencies (3125 and 14368 $\mathrm{Hz}$ ), and the vertical, co-planar coils had a wingtip separation of $21.4 \mathrm{~m}$. The recording was made 4 times per second, providing a 12-15 $\mathrm{m}$ sampling distance along the survey line. The system specifications are presented in more detail by Poikonen et al. (1998), Hautaniemi et al. (2005) and Suppala et al. (2005). Response amplitudes are high at the $30 \mathrm{~m}$ survey altitude used in Finland and Northern Scandinavia, but are also very effective at 40-60 m altitudes and across different geological terrains. The resolution characteristics of the system have been demonstrated from both a theoretical standpoint (Beamish, 2003a; Suppala et al. 2005) and in published case studies (Puranen et al. 1999; Beamish, 2003b).

Extending the bandwidth and improving the behaviour of AEM was one of the main R\&D targets of the JAC. The aim was to increase the vertical resolution of the system by widening the measurement frequency range with two more frequencies. Both geophysical and technical feasibility studies were carried out, and a four-frequency system was found to be realisable. The design of the AEM-05 system was based on the existing AEM-95 analogue tuned-coil technique. The AEM-95 system had proven characteristics of highly effective and stable signal-to-noise levels and so an incremental development route was taken.

The coils were again designed to be vertical-coplanar, and were developed and improved on the basis of the AEM-95 system. The main practical reason for this is that a horizontal or coaxial coil configuration would have been difficult to implement for structural (fixed-wing) reasons. The vertical coil configuration has a lower noise characteristic than horizontal coils installed across the wingtips; the latter tend to couple with the wingtip surface, causing disturbance to the coupling behaviour.

As a major part of Finland (the Finnish National Mapping Project) has been surveyed with the two-frequency system, it was natural to keep the middle two frequencies of the new system close to the existing frequencies. The additional two measurement frequencies were selected to be as high and low as possible with due consideration to the noise and structural issues. The sampling frequency is governed by a final-stage of low-pass filtering and the same $4 \mathrm{~Hz}$ sampling was retained.

Following the feasibility study, a new design of solid wingtip pods containing four coils with different diameters was constructed. As the weight of the four coils added to the stress of the aircraft wings, new materials and fixing options for the coils were studied in order to minimise the effects. The old coil structures were built using special avionic plywood. The new construction took advantage of modern, strong, lightweight and electrically insulating composite polymer resins. Using this approach, the total weight of the wingtip structures actually decreased slightly despite doubling the number of coils. Another advantage of the new structure is the teardrop design of the coil pod (Figure 1) that significantly reduces air resistance. 
The first geophysical test flights were flown during 2005 and showed very promising results, but the new strict aviation certification requirements (EASA) required much additional work thus delaying the productive use of the new system. The new system was finally used systematically on all surveys beginning in March 2006. Employing the existing technical solutions proved effective as the system noise levels were acceptable and the new frequencies were found to be highly valuable in interpreting the data.

A block diagram of the new 4-frequency system AEM-05 is shown in Figure 2. The system comprises transmitter electronics in the right wingtip, receiver coils in the left wingtip and signal processing electronics inside the aircraft. The transmitter (Tx) coils are air-cored tuned coils, the diameter of which varies between 0.50 and $0.60 \mathrm{~m}$.

Mutual coupling of coils is minimised by locating the coils sufficiently far from each other to maintain a high quality factor (Poikonen et al., 1998) and by providing axial offsets across the coil set. However, compared to the AEM-95 system in which a magnetometer was installed in both wingtips, the right wingtip (i.e. the transmitter side) magnetic sensor was transferred to a nose stinger, as the extra coils would have increased the noise levels of the magnetic sensor. The AEM-05 magnetic system now comprises a sensor in the left wingtip and in the nose stinger (Figure 1).

The receiver $(\mathrm{Rx})$ coils have dimensions similar to the transmitter coils. The signal at the Rx comprises both primary and secondary field components. Special compensation units are used to remove the primary field effect from the Rx signal before the separation of the signal into in-phase and quadrature components using lock-in amplifiers (Figure 2). The new specifications of the AEM-05 system are presented in Table 1.

\begin{tabular}{|l|l|l|l|l|}
\hline Frequency, $\mathrm{Hz}$ & 912 & 3005 & 11962 & 24510 \\
\hline Coil spacing, $\mathrm{m}$ & 21.35 & 21.35 & 21.38 & 21.38 \\
\hline Magnetic moment, $\mathrm{Am}^{2}$ & 190 & 127 & 49 & 27 \\
\hline
\end{tabular}

Table 1. Technical specifications of the AEM-05 system.

Noise in the measurement originates from several sources, e.g. the aircraft, instrument electronics and external sources such as power lines. The main noise source is the varying coil separation distance caused by the movement of the coils (wing-flexure) during flight. The rigid coil installation is designed to minimise the effect. The noise levels achieved depend on the frequency (lower frequencies having better signal-tonoise ratios) together with survey conditions, but noise figures for this system are generally around $20-30 \mathrm{ppm}$.

A particularly important technical characteristic of a wing tip EM system is the large coil-to-coil separation ( $>21 \mathrm{~m}$ in the case of the Twin-Otter). The improvement in signal/noise over smaller systems ensures that adequate signal can be obtained at a variety of survey heights. This is a critical factor when flying regulations preclude surveying at lower flight altitudes. 
A simple, but still diagnostic, way to analyse an AEM system is to study how it behaves above a homogeneous half-space. Theoretical responses of the Twin Otter system are shown in Figure 3. In-phase and quadrature responses are denoted by IP and $\mathrm{Q}$, respectively. The effective conductivity range of the AEM-05 system above a homogeneous half-space is about six decades wide ranging from less than $0.001 \mathrm{~S} / \mathrm{m}$ to more than $100 \mathrm{~S} / \mathrm{m}$. When the conductivity is low the response, particularly at low frequencies, may be influenced by the magnetic susceptibility effect, which has the same phase and direction as the primary field. With vertical coplanar coils, as in AEM-05, this causes a negative in-phase response. When the conductivity is high (conductivity-frequency large enough), the induced conductive response dominates the magnetic susceptibility effects. Between these ranges the effects of magnetic susceptibility and induced conductivity currents are mixed. Thus, at least in theory, the AEM measurements could also be utilized in joint AEM/magnetic modelling and inversion (Beard and Nyquist, 1998; Huang and Fraser, 2003; Farquharson et al., 2003). The in-phase measurements at the lowest frequency $(900 \mathrm{kHz})$ should prove to be particularly useful in this respect.

Comparison of the low to high frequency responses provides information about the distribution of electrically conductive units with depth. The apparent resistivity variations of the ground and the apparent depth of the model are routinely calculated using the standard Fraser half-space model (Fraser, 1978).

\section{Secondary systems}

Continuous local/regional/national scale surveying at a line spacing of $200 \mathrm{~m}$, across populated areas, ensures that all forms of infrastructure have the potential to interfere with the measurements. In addition, in an often-crowded airspace, our ability to perform surveys is always subject to regulatory conditions that may be tied to the density of structures/dwellings in the vicinity of each flight line. These may force a variety of flight elevations along each line. It should be noted that all towns and cities are overflown at the lowest permitted altitude, where possible, to maintain regional magnetic coverage.

The secondary data systems now being employed on JAC surveys enable a greater degree of understanding of the geophysical responses obtained. The sensitivity of our triaxial 50/60 Hz power line monitor (PLM) proves effective at the QC (Quality Control) level of data processing, in relation to the thousands of crossings of the major and minor power transmission grid. The PLM channel for each survey/block is also plotted as secondary data interpretation information.

Data from the recent Tellus airborne geophysical survey of Northern Ireland (Beamish and Leväniemi, 2006) are used to provide examples of the characteristics of the AEM05 system. Figure 4 is a location map of the 8 blocks that comprise the survey. The flight direction was $345^{\circ}$ and the flight line separation was $200 \mathrm{~m}$. The blocks are optimised to provide line lengths of 50 to $60 \mathrm{~km}$. The first example is taken at the regional scale provided by an entire survey block (E1 in Figure 4). Figure 5a,b show an example of secondary data amplitudes across the $\sim 37 \mathrm{x} 40 \mathrm{~km}$ survey block . Figure 5a shows a 3D perspective view of the radar altimeter (height above ground level) indicating the extent of high fly zones above the nominal survey altitude of 56 
m. Zones associated with two main towns ( $\mathrm{A}=$ Armagh and $\mathrm{N}=$ Newry), some smaller townships and major cross-country power line routes can be distinguished. The major power lines were flown at a higher than nominal survey altitude for safety reasons. Figure $5 \mathrm{~b}$ shows the corresponding PLM data. These data delineate the major crosscountry power line routes together with isolated and localised point sources of radiation. There is no response directly above the towns due to the higher altitude. The complex pattern observed across the lower margin of the image is of unknown origin. The robustness of the AEM data and the conductivity models derived from them, to power distribution noise (both radiative and coupling) remains a subject of ongoing research. In broad terms, the vertical coil-coil coupling arrangement appears remarkably robust to all but the largest radiative $50 / 60 \mathrm{~Hz}$ interference.

A downward-looking video camera (Figure 6) captures still images at a frame rate that is sufficient to allow overlap between successive images. Each frame is time-stamped to allow the images to be inserted into the survey database when performing QC operations. The frames are also used in the analysis/modelling of the data at the local scale. Figure 7 shows an example of a video frame inserted into a database examination of AEM channels. The cursor selection (vertical line) identifies the fiducial (Fid) location of the image (in this case, farm buildings). In this particular example, where the variations in the AEM data channels are obviously caused by variations in system altitudes (ground clearances), the lack of any induced secondary interference in the AEM data channels is evident. The main interference occurs in the magnetic data (not shown).

One requirement in airborne data processing is to determine the height of each sensor above the ground surface. The issue is more acute when low-level surveying is considered. Conventionally, this is achieved using a radar or laser altimeter. Both of these may be unreliable (i.e. biased to low values) when built structures are encountered. They can also be unreliable over tree canopy (Beamish, 2002). Due to the sensitivity of coupling ratios to altitude, our sensor noise figures theoretically require an elevation (above ground surface) accuracy of better than $0.10 \mathrm{~m}$; the precise figure depends on both ground conductivity and survey elevation. The effect on both half-space and multi-layer inversion models if incorrect altitude is used as an observed parameter can be highly significant.

In 2005, we introduced a dual pulse laser with a maximum sampling rate of $2 \mathrm{kHz}$. The device is shown in Figure 7. In practice, by operating the laser at $200 \mathrm{~Hz}$, an oversampling of $x 50$ is achieved in relation to the $4 \mathrm{~Hz}$ sampling of the AEM components. This form of redundancy in the sampling allows a post-processing algorithm, based on independent windows of 50 samples, to obtain an accurate (although necessarily spatially-averaged) estimate of height above ground surface across: (a) bodies of water, (b) most forms of canopy encountered and (c) built structures of limited spatial scale.

The increasingly quantitative uses being made of the AEM data also suggests that knowledge of the precise location of both transmitter and receiver in 3D space would be advantageous. Fitterman and Yin (2004) discuss the many aspects of bird manoeuvre distortion on frequency-domain helicopter-borne (HEM) responses. The JAC vertical coplanar (VCP) system is a unique fixed-wing configuration, but a VCP response did form part of the HEM study by Fitterman and Yin (2004). We are 
currently installing a GPS gyroscope to accurately monitor the pitch, heading and roll of the aircraft in conjunction with the data acquired. The gyroscope comprises 4 GPS receivers ( 1 master and 3 slaves) mounted in a diamond formation across the upper fuselage and wings of the aircraft. The device is intended as a research tool, for all the sensors, in the first instance.

\section{AEM Data Processing Software}

The ability to deliver good quality AEM data lies in the balance of in-field processing together with the post-processing procedures applied. In-field procedures take place in the aircraft (geophysical operator) and immediately following each sortie (QCgeophysicist). The in-field procedures provide the required survey acquisition QA (Quality Assurance) and are an efficient means of evaluating all the positional, geophysical and avionic channels and parameters from each flight.

The QC and processing procedures currently in place are described in detail by Hautaniemi et al. (2005). Of particular relevance here are the descriptions of the calibration of the AEM aboard the fixed-wing system. Accurate and reliable AEM data are only obtained through a series of carefully controlled methodological procedures:

- Pre-survey calibration (effect of the conducting aircraft)

- In-flight, out-of-ground effect calibration

- Interactive single-flight, zero-level correction for non-linear (e.g. thermal) drift

- Interactive single-line, zero-level correction across adjacent lines

The procedures are applied to individual components (in-phase and quadrature) of the coupling ratios at each frequency. Since these data form the basis of all subsequent AEM modelling, including the required half-space calculations, additional filtering (i.e. any form of spatial averaging) is avoided. This is in contrast to some noise reduction procedures (e.g. Hanning filters) routinely applied to raw HEM data sets (e.g. Tølbøll and Christensen, 2006).

The effect of the conducting aircraft and the method of calibration have been described by Suppala et al. (2005). According to the calculations presented, the effect of the conducting aircraft is small and can be accommodated by a pre-survey calibration carried out over the sea (e.g. Poikonen et al., 1998) at a variety of control heights (typically 20 to $100 \mathrm{~m}$ ).

In-flight, out-of-ground effect AEM system calibrations and their relationship with drift (zero-level) corrections are described in detail by Valleau (2000). The in-flight calibration of the JAC system is described by Hautaniemi et al. (2005). The calibration is performed at a high altitude (commonly $300 \mathrm{~m}$ above ground) at the beginning and end of each flight. A typical flight duration is 4 hours. The level of the AEM data can be corrected linearly using these calibration results. This preliminary automatic correction would provide adequate results if the drift were linear and low in magnitude. The linear part of the drift is usually less than $100 \mathrm{ppm}$ in an hour if there is a low temperature gradient. 
If the flight lines are long, the air temperature can sometimes vary significantly during a flight line, and this causes non-linear drift of the zero-level. A temperature variation of one degree centigrade changes the coil separation so that the zero-level may change by $70 \mathrm{ppm}$. It would be possible in theory to correct this effect, but unfortunately the wings of an aircraft cannot be regarded as a single rigid structure. There are also other reasons for this drift, such as the temperature variation of the coils and in other analogue components, which are never ideal. The non-linear drift must be estimated for each flight and for each AEM component. An interactive graphics program (EMprelev) is used to undertake this most important procedure. The user provides a set of points, which estimate the drift during that flight for each component. The nonlinear drift estimation for the fixed-wing data described briefly below can be compared with the linear drift estimation for HEM data described by Valleau (2000).

Figure 8 shows four data panels available in the leveling program. Figure $8 \mathrm{~d}$ shows one component of EM data $(912 \mathrm{~Hz}$, real component) for a complete survey flight (Flight 053, 17 flight lines) lasting 4 hours 10 minutes. Flight line lengths range from 30 to $40 \mathrm{~km}$. The flight lines, traversing both sea and land, are shown in Figure 4 (FL053) along the eastern seaboard. The sea was overflown to maintain magnetic coverage. This example was chosen because contrasting geological signatures are easy to identify in this setting. The example also shows the behaviour of the data in both highly conductive and resistive environments. Figure $8 \mathrm{~d}$ indicates the online/off-line data channel as a background to the recorded data. The flight and data recording start with a zero-level calibration at $\sim 300 \mathrm{~m}$. During the calibration stable and level flying is performed to allow the recording and confirmation of a zero-level calibration pulse. The aircraft then proceeds to the first survey line (Line 2496 in this example), descending to the nominal survey height of $56 \mathrm{~m}$. During off-line portions of the recording, the aircraft typically gains altitude and turns to reposition for the next survey line. Lines are not sequential when, as here, the flight line spacing is 200 $\mathrm{m}$. Following the final survey line (Line 2474 in this example), the aircraft attains a high altitude and again, during level flying, performs a final zero-level calibration. The interactive program allows the user to display both temperature and radar altitude (ground clearance) to aid the leveling procedure (Figure 8a,b). The outside temperature is plotted above the AEM profiles to help to determine whether a high temperature gradient exists. The altitude shown in Figure $8 \mathrm{~b}$ reflects the standard pattern of survey flying discussed above, together with any regulatory high-fly areas (in this case they only occur over land). The $912 \mathrm{~Hz}$ real data component is strongly influenced by the highly conductive seawater (producing high coupling ratios) and within each line the sea/land transition is easily identified. It should be noted that flight directions change between 345 and 165 degrees.

For comparison, the corresponding flight data for the $912 \mathrm{~Hz}$ imaginary component is shown in Figure 8e. The important feature in both data components is the background trend identified by the red line that traces the lowest data values, and joins the calibration points at the beginning and end of the flight. This type of non-linear trend is observed on every flight and in every component and is thus a characteristic feature of the behaviour of the data acquired by the fixed-wing system. The most common feature is an initial faster drift (red box in Figure 8d) followed by a slower drift throughout the remainder of the flight. The low-order nature of the trend, together with the nature of the survey flying pattern, suggests it is unlikely to be of geological origin. This characteristic behaviour is interpreted as the non-linear zero-level drift 
due to the superposition of all sources of drift. The blue line, indicating a linear drift between calibration points, is shown for comparison.

To perform non-linear zero-level corrections, the user has recourse to the data channels shown (Figure 8a,b,c,d) together with full zoom facilities. At the broad scale, as shown in Figure 8d, the user selects a series of points (red circles) at off-line locations using a mouse and cursor to define a drift curve through the lowest values. An adequate fit using the lowest number of control points is desired. As can be seen in the example of Figure 8, different numbers of control points are used in the two components. The result of the leveling modifications (corrected data) is shown interactively (Figure 8c). The user then zooms to a scale of individual lines (or less) to examine and refine the zero-levelling procedure. An example of this is shown in Figure 9. This shows detail from the real $912 \mathrm{~Hz}$ component in the red box (Figure 8d) from the calibration point and across the first two survey lines. The survey line lengths are about $30 \mathrm{~km}$. It is evident that across the onshore (lower amplitude) portions of the recording a series of spikes fall below the estimated red drift curve. It is at this point that knowledge of the geology and cultural noise sources influencing the data (what is actually being overflown) becomes important. In the example used, large amplitude excursions are present and are a consequence of the interference experienced when flying over populated areas. A particularly large example can be seen on the second line, following a regulatory high fly maneuver above a conurbation. The spikes are non-geological and are disregarded in relation to drift curve estimation. The procedure is carried out for each flight and for every component. The program tabulates and stores the results of the procedure resulting in an interpolation across time to provide a zero-level adjustment for every data point.

The preleveling is followed by a further line-by-line checking and adjustment (if required) of the zero levels of each line of data and of each component. A second graphical and interactive program (Level32) is used for this purpose. Lines are sequentially sorted in the data file, and adjacent profiles are compared to provide information about the line-to-line behaviour of the zero level. For each line, the user can provide a set of points, which determine the revised zero-level. Usually two points are enough to determine any residual small drift curve for correction. However, in case of a fast drift, three or more points, along an individual line, might be used.

In general terms, the use of the above procedures means that the AEM data from individual lines may be detrended (linear and non-linear) and a residual offset may be applied. These procedures are line-based and do not perturb the AEM data anomalies that have an expected wavelength much less than the line length and within the scale of the AEM footprint (Beamish, 2003a). The data provided are the most appropriate data for use in quantitative procedures (e.g. modeling/inversion) that require minimum filtering/distortion of individual anomalies.

As noted earlier, a simple way to classify the data is to calculate the apparent resistivity variations of the ground and the apparent depth of the model using the standard Fraser half-space model. Our preferred method is to use a look-up procedure that employs the in-phase and quadrature data components at each frequency to calculate apparent resistivity. In more detailed studies, multilayer inversion or 3D modelling is now practical, especially if background information on the electrical properties of the different geological units is available. 


\section{Vertical resolution analysis}

When AEM is applied at high resolution in areas containing potentially complex cover/bedrock relationships, the vertical discrimination of the system becomes significant. In a layered earth environment, the two additional frequencies at low and high frequencies should offer increased vertical resolution. This has been studied using a variety of synthetic models. The results of the 1D inversion studies presented here relate to the question: a) given no knowledge of the number of subsurface layers and $b$ ) given no knowledge of the true (rather than estimated) noise figures of our data, what is the likely configuration of the subsurface conductivity? This is an initial, pragmatic question that has to be applied to much regional scale data.

In order to address the first question, an Occam multi-layer procedure offering regularised, smooth models in the vertical direction is used (e.g. Farquharson et al., 2003). Such models cannot detect interfaces, nor recover 'true' layer conductivity values. To address the second condition, a variety of assumed noise figures must be considered and applied to the synthetic data (Constable et al., 1987).. The target misfit for the inversion is the chi-square expectation of the data. The chi-square expectation value is 8 for our 4 frequency data and 4 for the 2 frequency data. A 5-layer model is considered, The model comprises 2 conductive layers $(100 \mathrm{mS} / \mathrm{m})$ in a resistive $(1$ $\mathrm{mS} / \mathrm{m}$ ) host. The first conductive layer has a thickness of $5 \mathrm{~m}$ and is located between depths of 10 and $15 \mathrm{~m}$. The second conductive layer has a thickness of $20 \mathrm{~m}$ and is located between depths of 60 and $80 \mathrm{~m}$. The question posed is to what extent the 2 and 4 frequency data can resolve the 2 conductive features. When applied to a synthetic model data obtained from interfaces, the Occam procedure will not recover 'true' layer conductivity values.

The smooth Occam model results presented in Figure 9 relate to a 31 layer model with layer thicknesses set at $4 \mathrm{~m}$. The synthetic data were obtained assuming a survey elevation of $60 \mathrm{~m}$. The frequencies used in the 4 frequency inversion were 912, 3005, 11962 and $24510 \mathrm{~Hz}$. The frequencies used in the 2 frequency inversion were 3005 and $11962 \mathrm{~Hz}$ and are thus similar to those of the previous AEM-95 system. Two sets of results are shown assuming noise in the data exists at the $5 \%$ and $1.25 \%$ levels. Thus in the $2 \mathrm{f}(5 \%)$ result (obtained from 2 frequency inversion and assuming a $5 \%$ noise level), the model conductivity values range from only 14 to $73 \mathrm{mS} / \mathrm{m}$, the model is highly smooth and only marginally detects the lower conductor. The corresponding 4 frequency model displays a larger data value range and the near-surface conductor is detected. The corresponding models assuming $1.25 \%$ noise are also shown. These clearly offer improved performance, since the data is assumed to be more accurate. The improved detection performance of the 4 frequency system is demonstrated at both of the 2 noise levels considered. The 4 frequency data clearly offer improved discrimination of conductive features at both shallow and deeper levels.

\section{Applications}

As far as we are aware, the only high-resolution national scale map of subsurface (half-space) resistivity is that provided by GTK as derived from their National 
Mapping Project (Peltoniemi, 2005). The $3 \mathrm{kHz}$ measurement (although in different configurations) has had a particular longevity being introduced in 1972 at the beginning of the current mapping project. Our new system retains this tradition. The AEM data provided by this project have been used in a wide variety of applications, in conjunction with the associated magnetic and radiometric information.

As in much of the northern European shield area, a primary use of the AEM information relates to mineral exploration. Some of these primary mapping investigations are reported by Turunen et al. (2005), Lohva and Lehtimaki (2005) and Airo (2005). Increasingly, through the 1990's and into the new century, the AEM data were used in a variety of environmental studies in Finland and across Europe. A series of case studies relating to the environmental applications (groundwater and contaminated land) of the data is presented by Lahti et al. (2005). In the UK, particular attention has been paid to landfill, brownfield and mine-site investigations (Beamish, 2003b; Beamish and Klinck, 2006). Although national scale surveying at a line spacing of $200 \mathrm{~m}$ is adopted both in Finland and the UK, the case for localised infill lines to provide the highest resolution should always be considered for environmental type investigations.

When AEM measurements are routinely obtained (alongside magnetic and radiometric data), the AEM data immediately begin to fill an existing geophysical knowledge gap. Even in countries, such as the UK, that can be considered to have well-mapped geological formations, we have scant knowledge of the bulk conductivities of these formations. Add to this the ability to reveal concealed structure, and the data have the potential to make significant discoveries at a wide range of scales. Figure 10 shows an example of this at the regional/national scale obtained with the new AEM-05 system. The image shown is a shaded-relief image of the $3 \mathrm{kHz}$ half-space conductivity map from the survey area shown previously in Figure 4 (Block E1). Shaded-relief is a useful method of displaying the highwavenumber content of the lateral conductivity contrasts and is typically used to delineate faults, thrusts and offsets in geophysical data sets. Swathes of conductive features (partially outlined within the ellipse) traverse the area with a NE-SW strike.

The central part of the area comprises a sequence of resistive Silurian greywackes (mudstones and siltstones) that are the remnants of an accretionary prism formed during the closure of the Iapetus ocean (Mitchell, 2004). The cross-cutting heavy blue lines outline the tract boundaries obtained from the 1:250k geological map. Inversion models (not shown here) of the conductive features indicate that they are all concealed. They are interpreted as the bentonite rich, Moffat shales formed from the pelagic muds of the descending oceanic crust. As such, they are important marker horizons within the tectonostratigraphic geological model. As can be seen in Figure 10 , the newly revealed subsurface geophysical information departs significantly from the existing geological mapped interpretation.

The application of the data to site-investigation scale issues involves focussing on data tiles that are typically no more than $3 \times 3 \mathrm{~km}$ in extent. It is at this point that a wide-range of existing databases (e.g. GIS applications) may be invoked to assist with investigations that become increasingly forensic in scope. As an example, Figure 11 shows the apparent conductivity data, from all 4 frequencies of the JAC- 05 system, observed across a $3 \times 2 \mathrm{~km}$ area. The data is again taken from the recent Tellus survey 
of Northern Ireland (Beamish and Leväniemi, 2006). The location of the selected rectangle is shown and arrowed in Figure 4. The first data frame (Figure 11a, $912 \mathrm{~Hz}$ ) is displayed on a background 1:50k topographic map. The sampling provided by the $200 \mathrm{~m}$ flight lines $\left(345^{\circ}\right)$ is also shown. A database provided the locations of 2 landfills (these often refer to a site office) within the area and these are shown with symbols. As in much of the UK, the central landfill occupies a former quarry. The landfill is a modern, engineered structure, with liner, that has been in operation for about 6 years. Further detailed study of the data reveals that the largest amplitudes are closely associated with the location of the operational landfill. The data for the other 3 frequencies (Figure 11b,c,d), are shown in relation to a single flight line (1228) that crosses the peak amplitudes associated with the landfill. The data are plotted using the same colour scale. Peak amplitudes associated with the landfill are $51 \mathrm{mS} / \mathrm{m}(912 \mathrm{~Hz}$, Figure 11a), $90 \mathrm{mS} / \mathrm{m}(3005 \mathrm{~Hz}$, Figure 11b), $179 \mathrm{mS} / \mathrm{m}(11962 \mathrm{~Hz}$, Figure 11c) and $193 \mathrm{mS} / \mathrm{m}(24510 \mathrm{~Hz}$, Figure 11d). The second, older quarry/landfill site in the east displays a different frequency dependence, peaking in amplitude at a frequency of $11962 \mathrm{~Hz}$ (Figure 11c).

A number of cultural influences on the data are apparent, particularly at the lowest frequencies. The northwest corner of the area contains two caravan (static holiday homes) sites. These both provide EM couplings that decay with frequency. A linear feature associated a road in the central south area can also be observed at the lower two frequencies.

Even with the mapping information provided by the half-space models from four frequencies, our understanding of the behaviour of the conductivities across the site remains limited. It is evident from the results presented, that large scale conductivity gradients exist and that any subsurface model is likely to be 3 dimensional. This is a persistent feature of much of our site-scale applications. It should also be noted that, given this type of behaviour, half-space apparent conductivity models can only be regarded as approximate, although they remain relevant and highly useful.

Increased understanding of the data is obtained by performing 1D inversion, of the 4 frequency data, along a flight line. The underlying axiom is that this is necessarily approximate, but nevertheless, useful. A regularised inversion, such as the Occam procedure, provides a useful conservative approach to defining the most likely vertical configuration of conductive features within the subsurface. The example shown here uses flight line 1228 identified in Figure 11. Flight elevations range from 40 to $69 \mathrm{~m}$, there are no radiative effects detected by the PLM and data qualities appear good. The Occam inversion assumed a $2.5 \%$ noise level in all the channels. The inversion achieved chi-squared misfits close to the expectation level (8) apart from across the central landfill site where near-surface lateral gradients in conductivity appear strongest (Figure 11). The misfit together with the observed and modelled data at the lowest and highest frequencies (the additional frequencies provided by the AEM-05 system) are shown in Figure 12.

The $2 \mathrm{~km}$ conductivity cross-section is shown in Figure 13. It is perhaps worth pointing out that the large majority of landfills studied provide quite simple models often confined to the near-surface. This particular example displays complex, highly conductive pathways suggesting links between the near-surface and much deeper 
conductive units. The conductivity amplitudes (the maximum is $>500 \mathrm{mS} / \mathrm{m}$ ) and implied volumes of the deeper conductor suggest a natural, rather than artificial, source. It should also be noted that the thickness of the deep conductor is largely a modelling artefact; the conductive unit is effectively indistinguishable from a lower conductive half-space. There is probably a screening effect in the center of the profile due to the near-surface conductive zone. It should also be acknowledged that an estimation of depths of investigation would require three dimensional modelling for this particular example.

The site is about $2.25 \mathrm{~km}$ from the coast (Figure 4) and is situated within the Antrim basalt formations (Lower and Interbasaltic Formations). Part of the sequence comprises massive columnar basalts, as typified by the Giant's Causeway, on the coast nearby. Joints and pipe vesicles are a feature of the geological setting. It is possible that the deeper conductive units represent pockets of deep, inland conductive brines. Their continuity coastwards is not, however, confirmed using the regional scale data. The distribution of conductive materials in the vicinity of the landfill site remains subject to further, follow up, investigations. This requirement for follow-up work is a pervasive outcome of the application of our airborne AEM data sets to features detected at the local scale.

\section{Summary}

This paper has reported a recent upgrade of the JAC AEM system (AEM-05), mounted as vertical coplanar coils on a DeHavilland Twin-Otter aircraft. The wing-tip coil system now operates at 4 frequencies across a bandwidth from 0.9 to $25 \mathrm{kHz}$. The system builds on decades of experience and has now been fully operational for 1 year, acquiring 3-in-1 data across Europe. During the first year of AEM-05 operations we acquired 85,000 survey line-km during $\sim 700$ flying hours. The main component of the operations involved regional National Survey acquisition in Finland and the UK. Secondary systems comprising laser altimeter, digital video and power line monitor have also been introduced to support the primary geophysical data sets. Survey data volumes at this level require efficient processing software that maintains the integrity of the AEM data. These have been briefly described. As with all frequency-domain AEM systems, achieving the correct zero levels in amplitude and phase across the spectral bandwidth of the system is the most challenging and time-consuming procedure. The enhanced resolution capabilities of the AEM-05 system were studied and a simple theoretical example using Occam inversion has been presented.

It has been pointed out that routine application of AEM surveying is capable of generating new knowledge at a wide range of scales. This stems, in part, from the lack of existing information regarding bulk conductivities and their spatial variations. Two application studies were presented to demonstrate this point at the national/regional and local scales. In both cases, the information obtained from the AEM data is acutely revealing in terms of the previously unknown subsurface variations in conductivity. 


\section{Acknowledgements}

We acknowledge, with much appreciation, the support, skills and professionalism of the aircrew of the Finnish Aviation Academy. This report is published with the permission of the Executive Director, British Geological Survey (NERC) and the Programme Manager of the Geological Survey of Finland (GTK). 


\section{References}

Airo, M-L. (Ed.), 2005a. Aerogeophysics in Finland 1972-2004: Methods, System Characteristics and Applications, Geological Survey of Finland, Special Paper 39, 1197.

Airo, M-L., 2005b. Regional interpretation of aerogeophysical data: extracting compositional and structural features. In: Airo, M-L. (Ed.) Aerogeophysics in Finland 1972-2004: Methods, System Characteristics and Applications, Geological Survey of Finland, Special Paper 39, 176-197.

Beamish, D., 2002. The canopy effect in airborne EM. Geophysics 67, 1720-1728.

Beamish, D., 2003a. Airborne EM footprints. Geophysical Prospecting 51, 49-60.

Beamish, D. 2003b. Characterising landfills from the air. First Break 21, 67-72.

Beamish, D., Klinck, B., 2006. Hydrochemical characterization of a coal mine plume detected by an airborne geophysical survey. Geofluids 6, 82-92.

Beamish, D., Leväniemi, H., 2006. The Tellus airborne geophysical survey of Northern Ireland. EAGE Near-Surface Conference 2006, Helsinki, Extended Abstracts, Paper B022.

Beard, L.P., Nyquist, J.E., 1998. Simultaneous inversion of airborne electromagnetic data for resistivity and magnetic permeability. Geophysics 63, 15561564.

Constable, S.C., Parker, R.L., Constable, C.G., 1987. Occam's inversion: a practical algorithm for generating smooth models from electromagnetic sounding data. Geophysics, 52, 289-300.

Farquharson, C.G., Oldenburg, D.W., Routh, P.S., 2003. Simultaneous 1D inversion of loop-loop electromagnetic data for magnetic susceptibility and electrical conductivity. Geophysics 68, 1857-1869.

Fitterman, D.V.,Yin, C., 2004. Effect of bird manoeuvre on frequency-domain helicopter EM response. Geophysics 69, 1203-1215.

Fraser, D.C., 1978. Resistivity mapping with an airborne multicoil electromagnetic system. Geophysics 43, 144-172.

Hautaniemi, H., Kurimo, M., Multala, J., Leväniemi, H., Vironmäki, J. 2005. The 'three in one' aerogeophysical concept of GTK in 2004. In: Airo, M-L. (Ed.) Aerogeophysics in Finland 1972-2004: Methods, System Characteristics and Applications, Geological Survey of Finland, Special Paper 39, 21-74.

Huang, H., Fraser, D.C., 2003. Inversion of helicopter electromagnetic data to a magnetic conductive layered earth, Geophysics 68, 1211-1223. 
Lahti, M., Vanhala, H., Mattsson, A., Beamish, D., Lerssi, J. 2005. Environmental applications of airborne geophysics - groundwater and contaminated soil in Finland, Germany and United Kingdom. In: Airo, M-L. (Ed.) Aerogeophysics in Finland 19722004: Methods, System Characteristics and Applications, Geological Survey of Finland, Special Paper 39, 155-175.

Lohva, J., Lehtimäki, J., 2005. Geophysical investigation of kaolin and ilmenite deposits in Finland. In: Airo, M-L. (Ed.) Aerogeophysics in Finland 1972-2004: Methods, System Characteristics and Applications, Geological Survey of Finland, Special Paper 39, 147-154.

Mitchell, W.I. (Ed.), 2004. The geology of Northern Ireland - Our Natural Foundation. Geological Survey of Northern Ireland, Belfast.

Peltoniemi, M. 2005. Airborne geophysics in Finland in perspective. In: Airo, M-L. (Ed.) Aerogeophysics in Finland 1972-2004: Methods, System Characteristics and Applications, Geological Survey of Finland, Special Paper 39, 7-20.

Poikonen, A., Sulkanen, K., Oksama, M., Suppala, I. 1998. Novel dual frequency fixed wing airborne EM system of Geological Survey of Finland (GTK). Exploration Geophysics 29, 46-51.

Puranen, R., Säävuori, H. Sahala, L. Suppala, I. Mäkilä, M., Lerssi, J. 1999. Airborne electromagnetic mapping of surficial deposits in Finland. First Break 17 (5), 145-154.

Suppala, I., Oksama, M., Hongisto, H. 2005. GTK airborne EM system: characteristics and interpretation guidelines. In: Airo, M-L. (Ed.) Aerogeophysics in Finland 1972-2004: Methods, System Characteristics and Applications, Geological Survey of Finland, Special paper 39, 103-118.

Tølbøll, R.J., Christensen, N.B., Robust 1D inversion and analysis of helicopter electromagnetic (HEM) data. Geophysics 71, 53-62.

Turunen, P., Vanhanen, E., Pankka, H., 2005. Application of low altitude airborne geophysics to mineral exploration in the Kuusamo schist belt, Finland. In: Airo, M-L. (Ed.) Aerogeophysics in Finland 1972-2004: Methods, System Characteristics and Applications, Geological Survey of Finland, Special paper 39, 137-146.

Valleau, N.C., 2000. HEM data processing - a practical overview. Exploration Geophysics 31, 584-594. 


\section{Figure Captions}

Figure 1. The new AEM-05 four-frequency wingtip installation and new magnetic nose stinger.

Figure 2. Schematic block diagram of the four-frequency system. Tx refers to a coil transmitter. Rx refers to a coil receiver. The CPU unit terminates in a data bus.

Figure 3. Theoretical AEM-05 responses as a function of half-space conductivity. Inphase responses plotted with solid lines, quadrature responses with dotted lines. The magnetization (magnetic susceptibility) effect is also plotted at the lowest $(912 \mathrm{~Hz}$ ) frequency. Relative magnetic permeability is denoted by $\mu_{\mathrm{r}}$.

Figure 4. Location map. The 8 survey blocks (A to E2) of the Tellus aerogeophysical survey of Northern Ireland. Blue outline is coastal boundary. Red outline is onshore border with the Republic of Ireland. Locations of 3 data sets referred to in the text are arrowed. The coordinate grid is the Irish National Grid.

Figure 5. Survey block E1 (see Figure 4) in Northern Ireland (37 x $40 \mathrm{~km})$ showing as

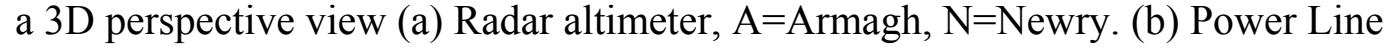
Monitor (PLM).

Figure 6. Rear measurement panel of survey aircraft containing digital camera (left) and laser altimeter (right).

Figure 7. Example of database examination of EM data. Grid of EM data (in-phase component at $3 \mathrm{kHz}$ ) with flight lines (top left). Digital image at cursor location (bottom left). Database channels and plots of EM components ( 2 frequencies), radar altimeter, GPS_height, and digital elevation data, and (lower most) power line monitor.

Figure 8. Example of drift correction (data preleveling) using data from a complete flight (Flight 053). The abscissa is linear time over the duration of the flight (4 hours 10 minutes). The data panels a,b,c and $d$ are available within the interactive program for the example data which is the in-phase (real) component at $912 \mathrm{~Hz}$. (a) Outside (the plane) temperature. (b) Radar altitude. (c) Corrected data. (d) Raw data on a background of the on/off line channel defining the $17 \mathrm{flight}$ lines acquired. The red circles are the user picks of the zero-level. The red box defines a time frame examined in greater detail in Figure 9. (e) The corresponding data for the quadrature component at $912 \mathrm{~Hz}$, in which the hand-picked drift curve is compared with a linear drift curve between calibration points.

Figure 9. Detail from the previous plot (red box, Figure 9d) showing the behaviour of the data from the initial calibration point and across the first two survey lines. The online lengths of the two survey lines are about $30 \mathrm{~km}$. The large amplitude response across the offshore portion of the survey lines has been cropped (for clarity).

Figure 10. 1D models obtained by Occam inversion of a synthetic data set using twofrequency (2f) and four-frequency (4f) data and assuming five percent data noise (5\%) and 1.25 percent data noise $(1.25 \%)$. The two target conductive zones are shaded. 
Figure $11.3 \mathrm{kHz}$ half-space conductivity of survey block (E1) in Northern Ireland (37 x $40 \mathrm{~km}$ ) shown as shaded-relief image (light source due west). Heavy blue lines are geological boundaries and faults/tracts from the 1:250k geological map. The ellipse defines the area of conductivity contrasts discussed in the text.

Figure $12.3 \times 2 \mathrm{~km}$ area from block C2 in Northern Ireland showing apparent conductivity in $\mathrm{mS} / \mathrm{m}$ at 4 frequencies, all using the same colour scale. (a) $912 \mathrm{~Hz}$ apparent conductivity on a background 1:50k topographic map, together with flight lines $\left(345^{\circ}\right)$. Two cross symbols denote landfill sites. (b) $3005 \mathrm{~Hz}$ apparent conductivity with flight line 1228. (c) $11962 \mathrm{~Hz}$ apparent conductivity with flight line 1228. (d) $24510 \mathrm{~Hz}$ apparent conductivity with flight line 1228.

Figure 13. Results from Occam inversion of 4 frequency data along flight line 1228. Upper 2 panels show observed and modelled data at the lowest $(912 \mathrm{~Hz})$ and highest $(24510 \mathrm{~Hz})$ frequencies. P refers to the in-phase and Q refers to the quadrature component. Observed data shown with symbols, modelled data with lines. Lower panel shows chi-square misfit.

Figure 14. Conductivity cross-section along a $2 \mathrm{~km}$ section of flight line 1228, obtained by Occam inversion. Vertical exaggeration x10. 


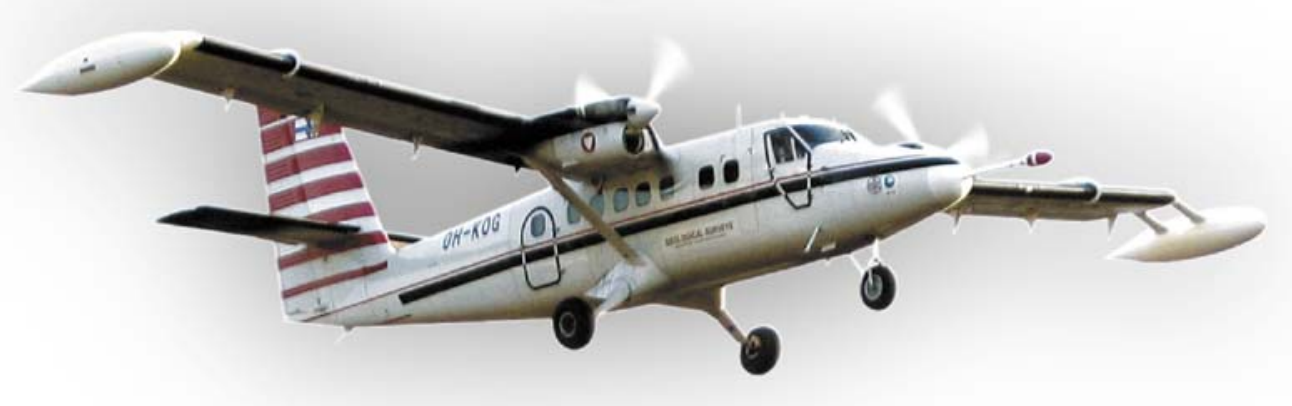

Figure 1

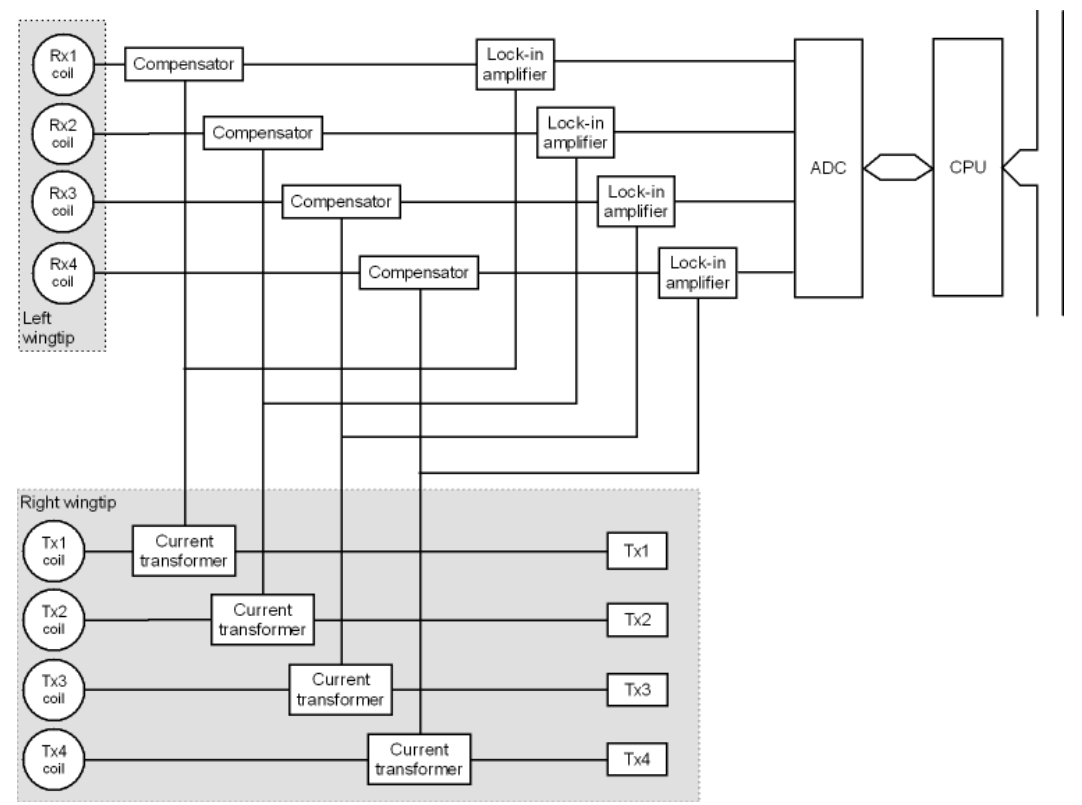

Figure 2 


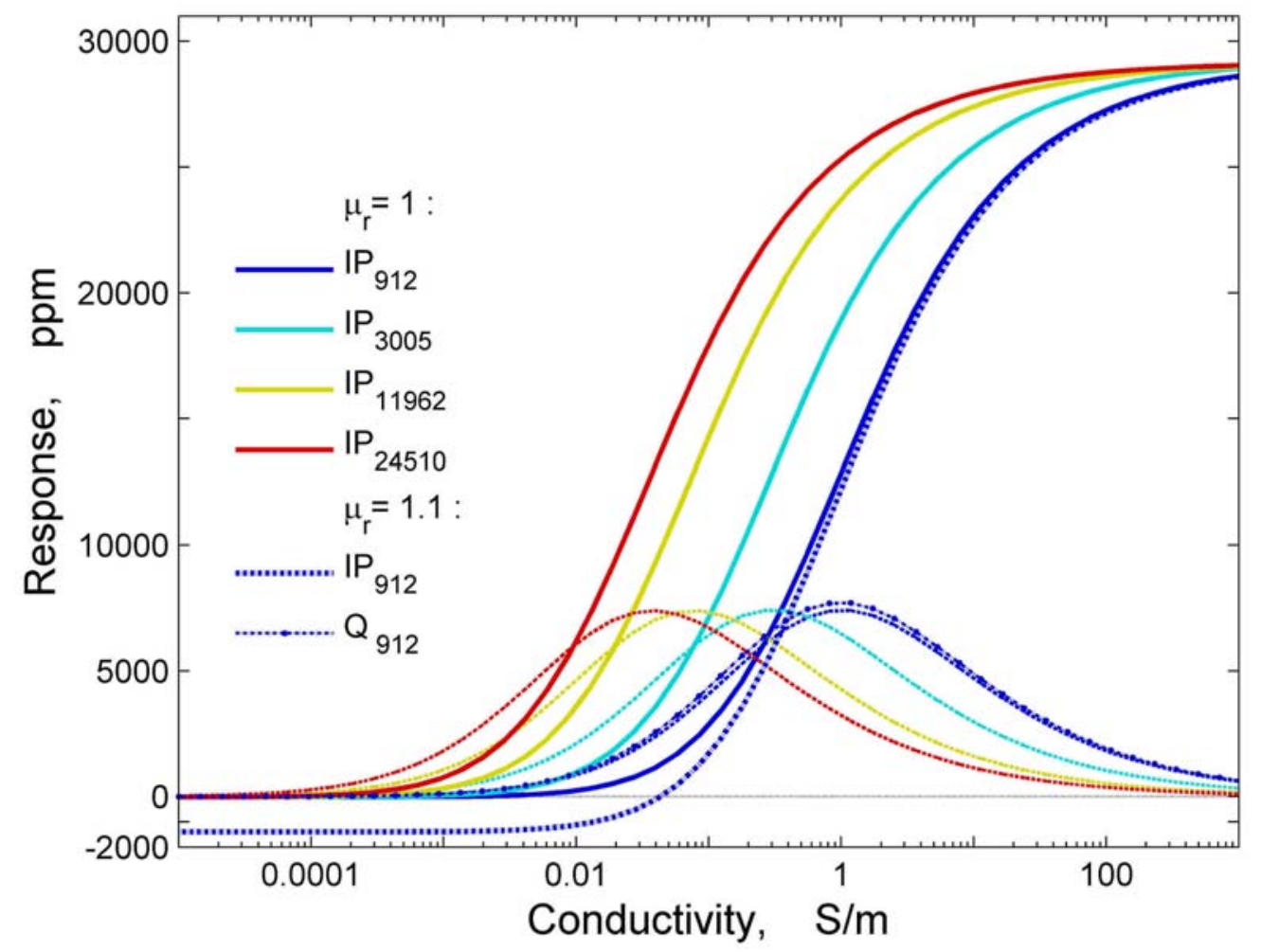

Figure 3

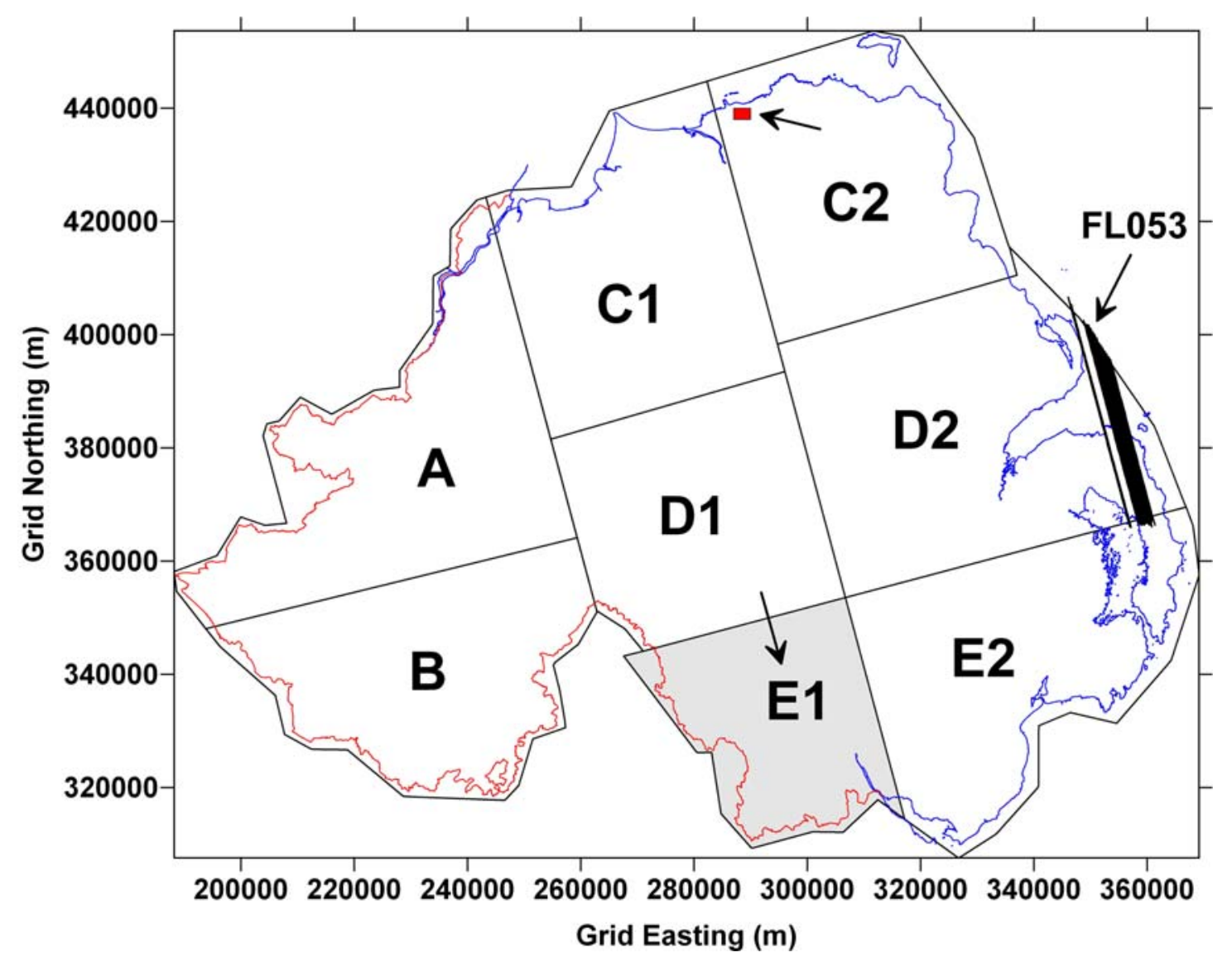

Figure 4 


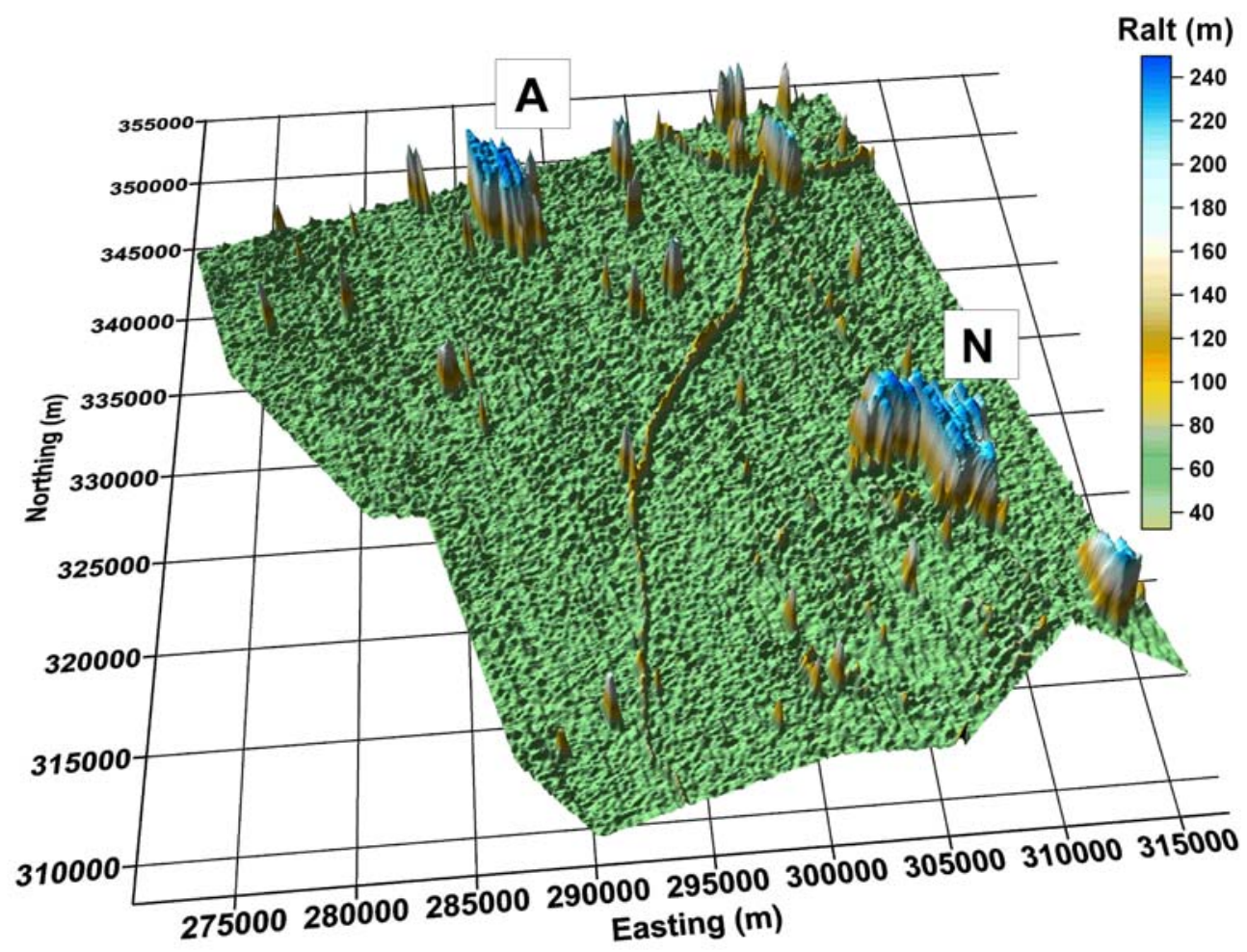

(a)

Figure $5 a$

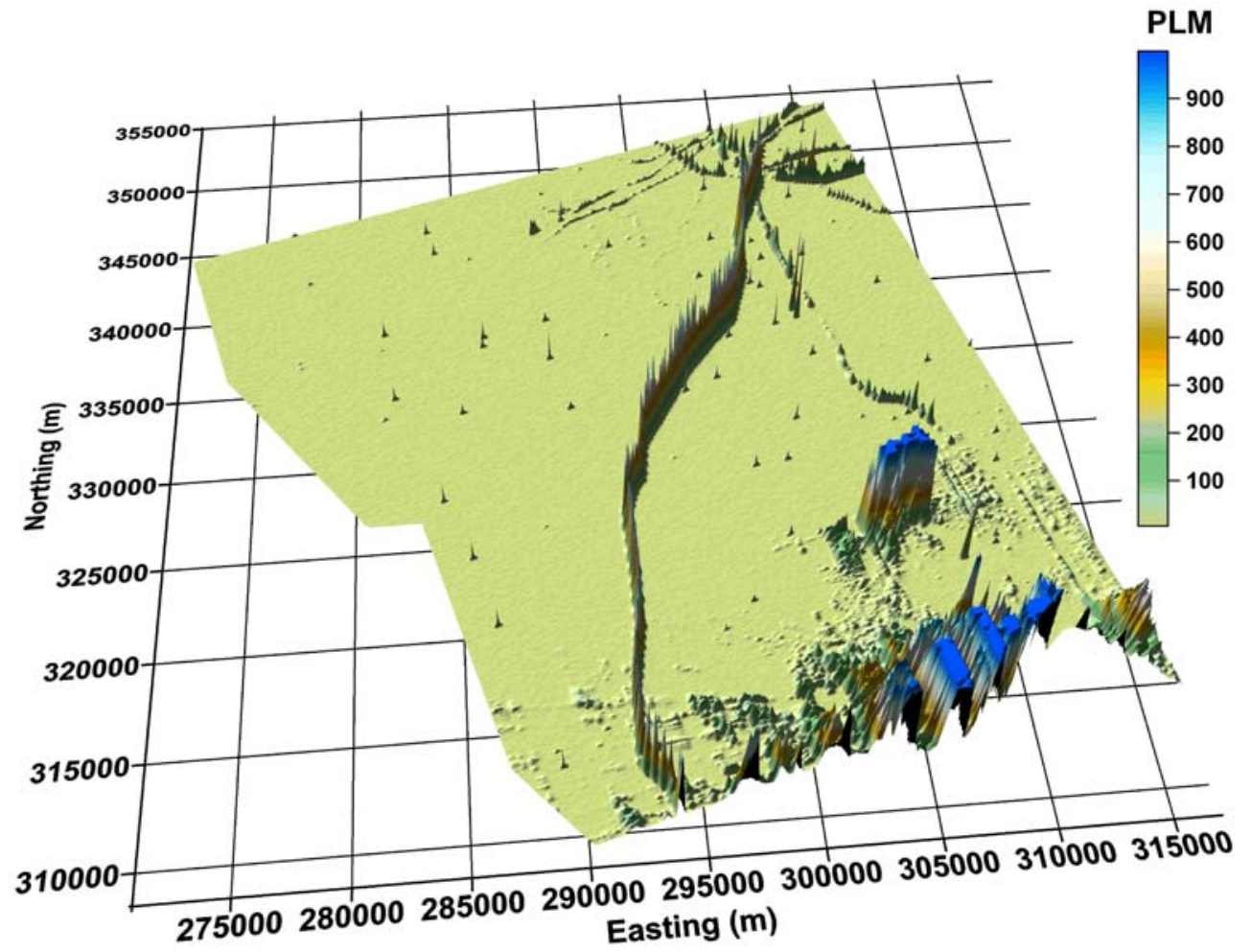

(b)

Figure $5 b$ 


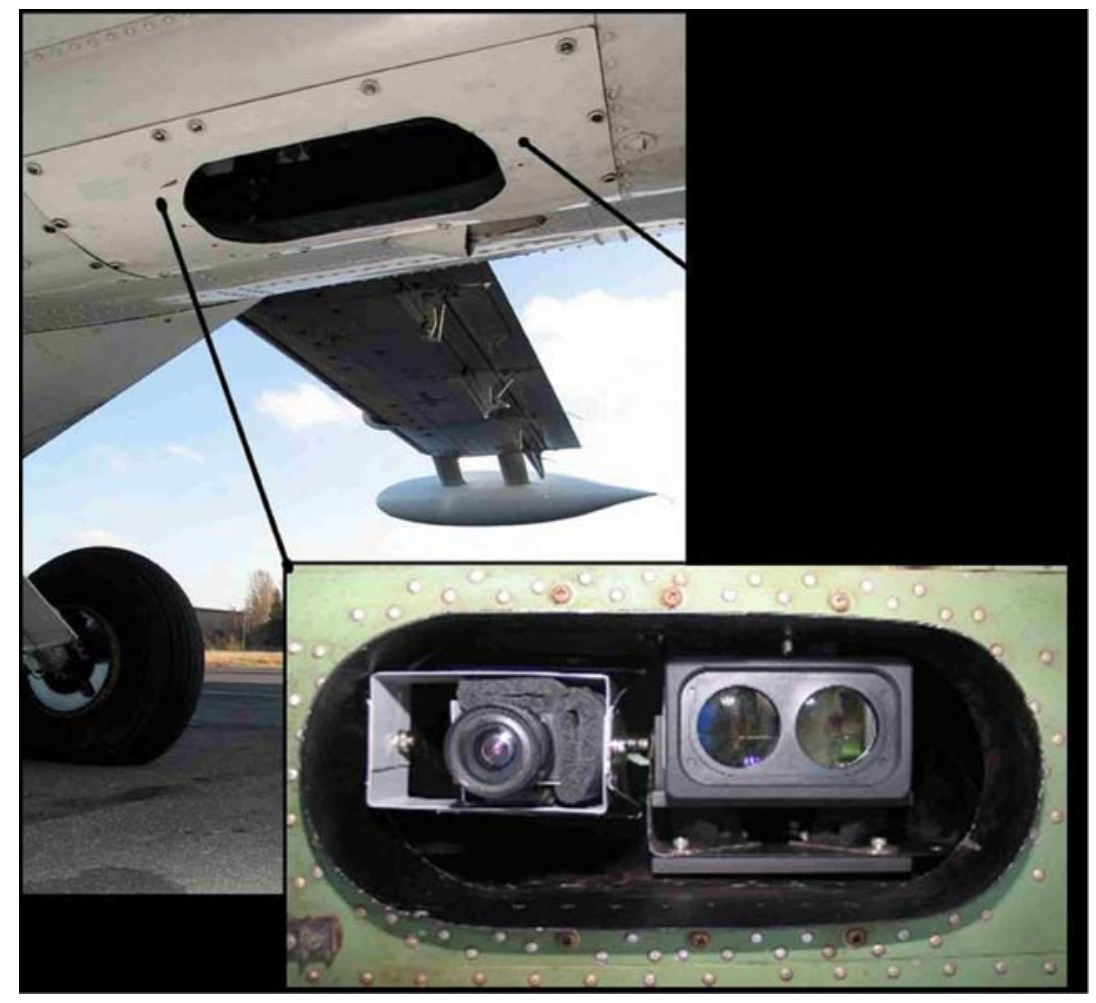

Figure 6

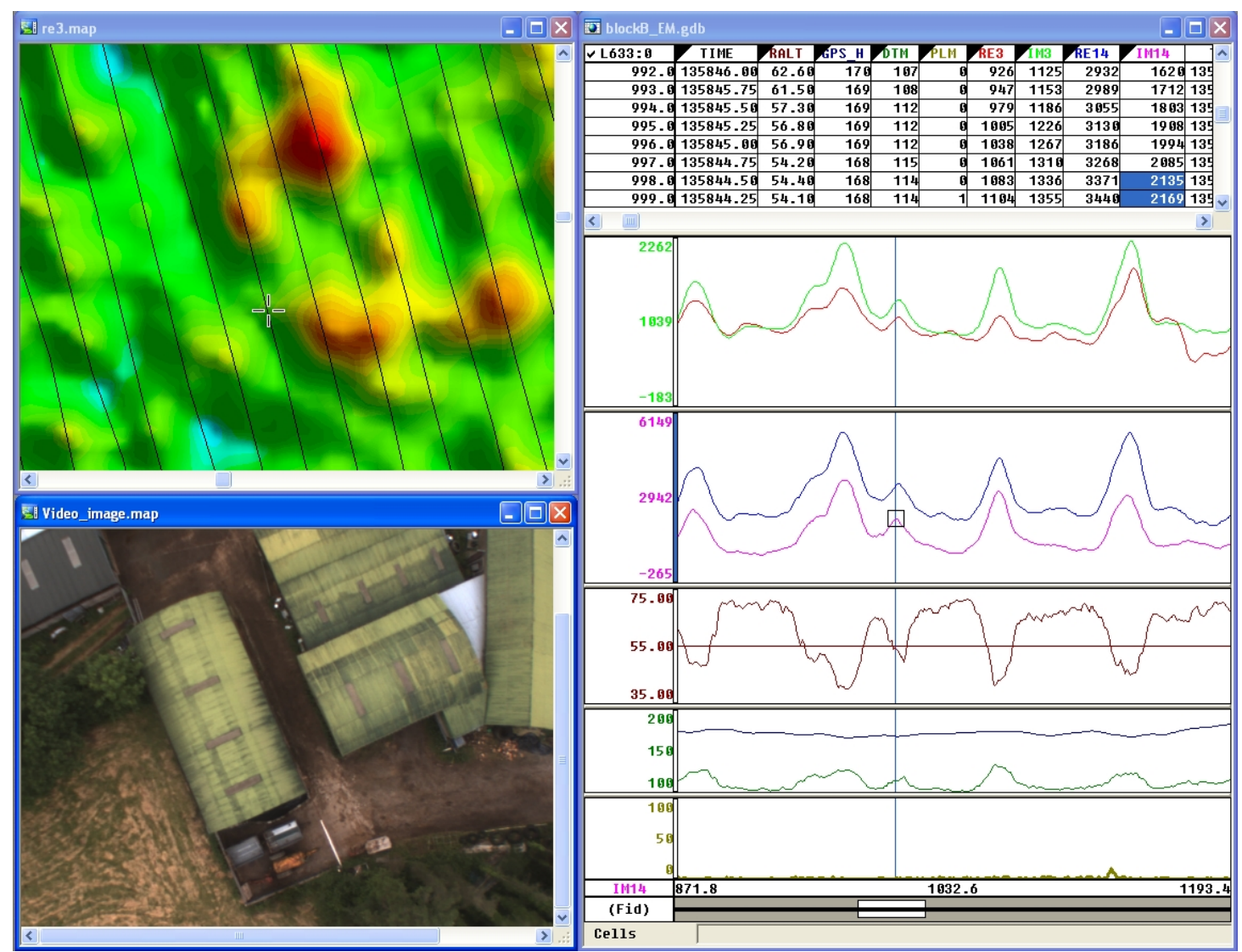

Figure 7 
(a)

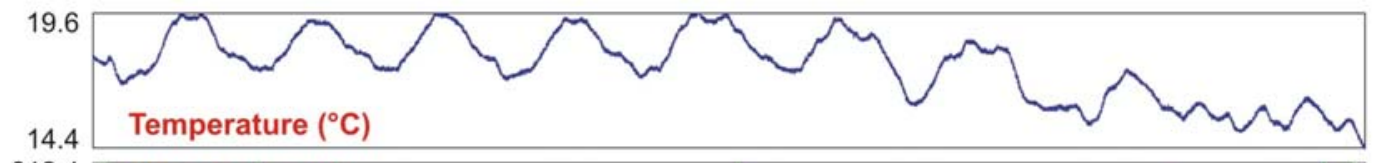

(b) 212.4 Altitude (m.agl)

(c) 35.6

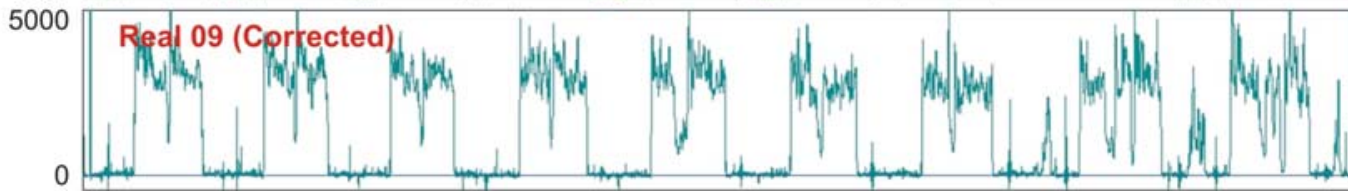

(d)
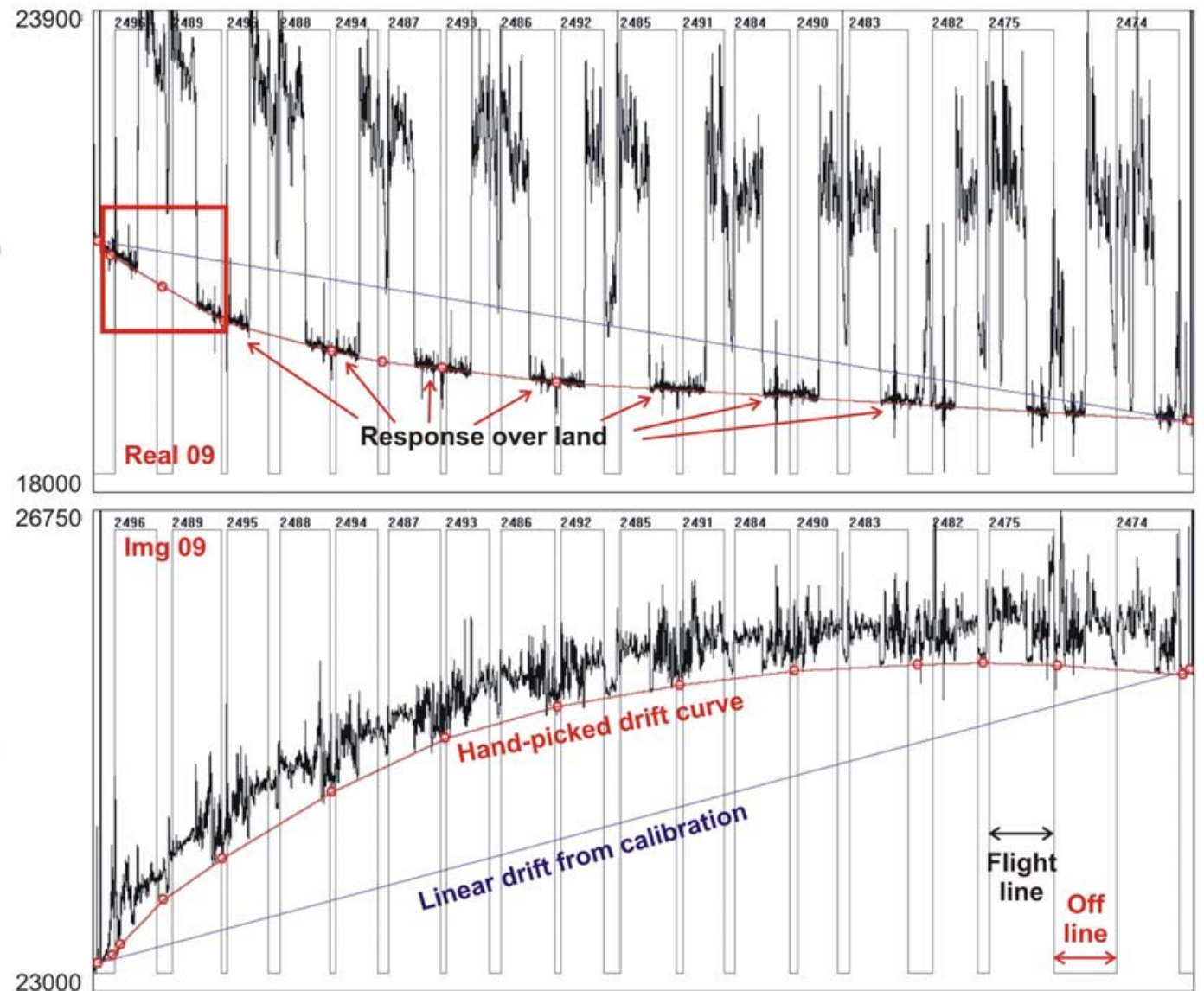

Figure 8 
(a)

(b)

$$
212.4 \text { Altifude (m.agl) }
$$

(c)

|

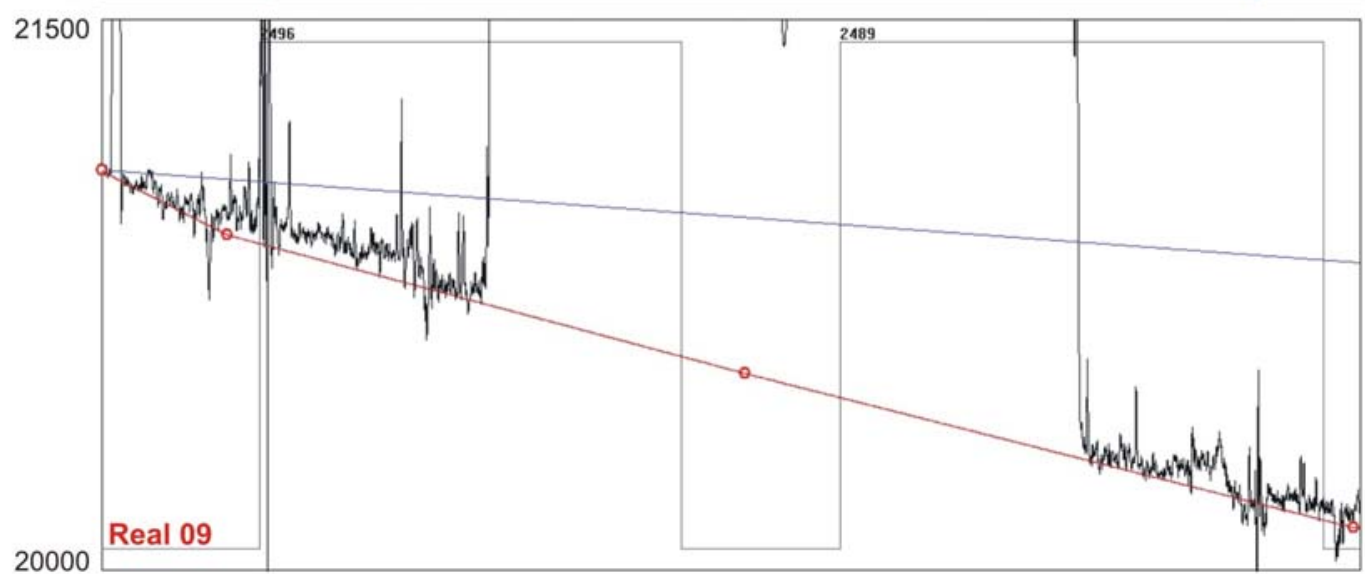

Figure 9

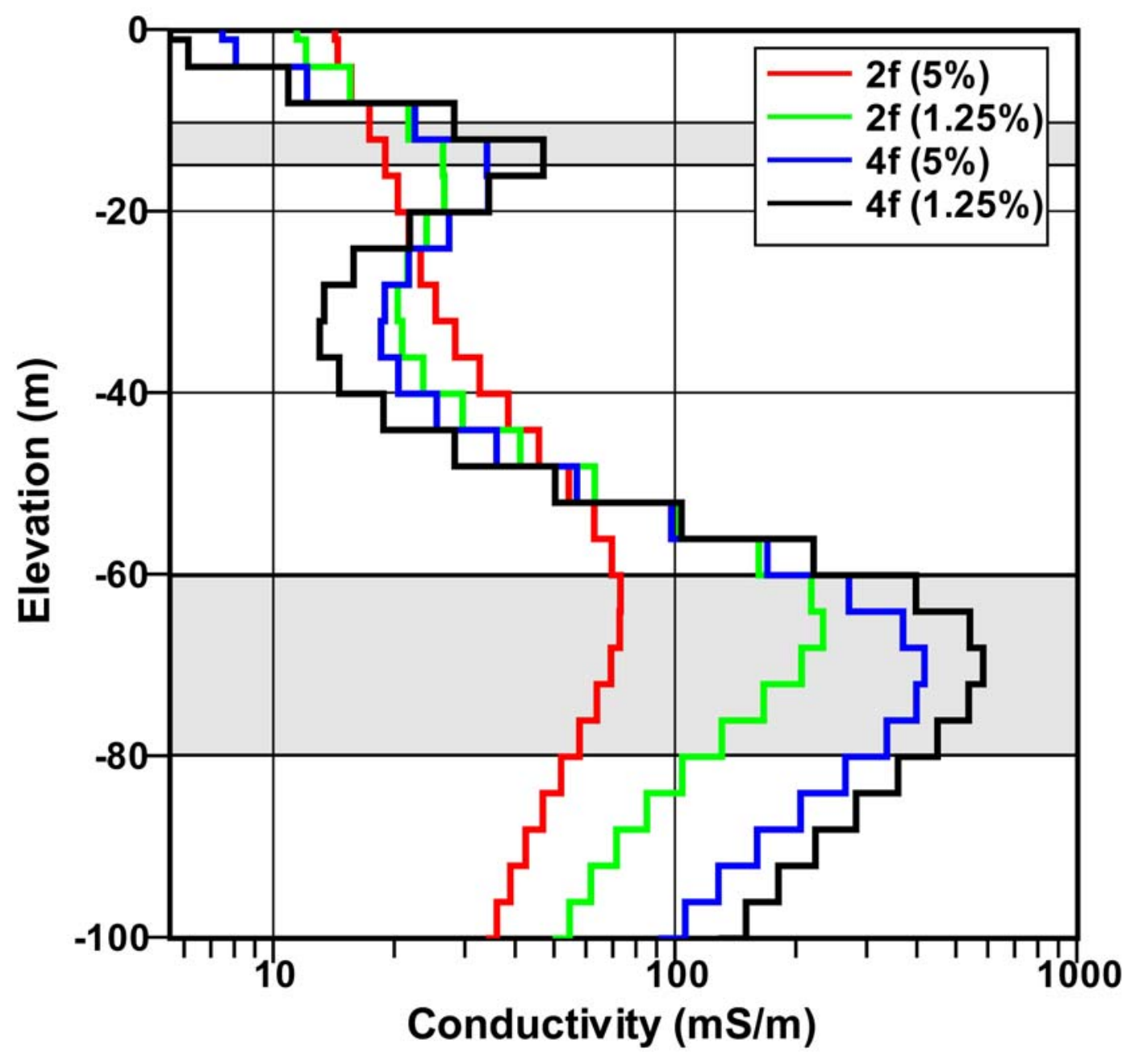

Figure 10 


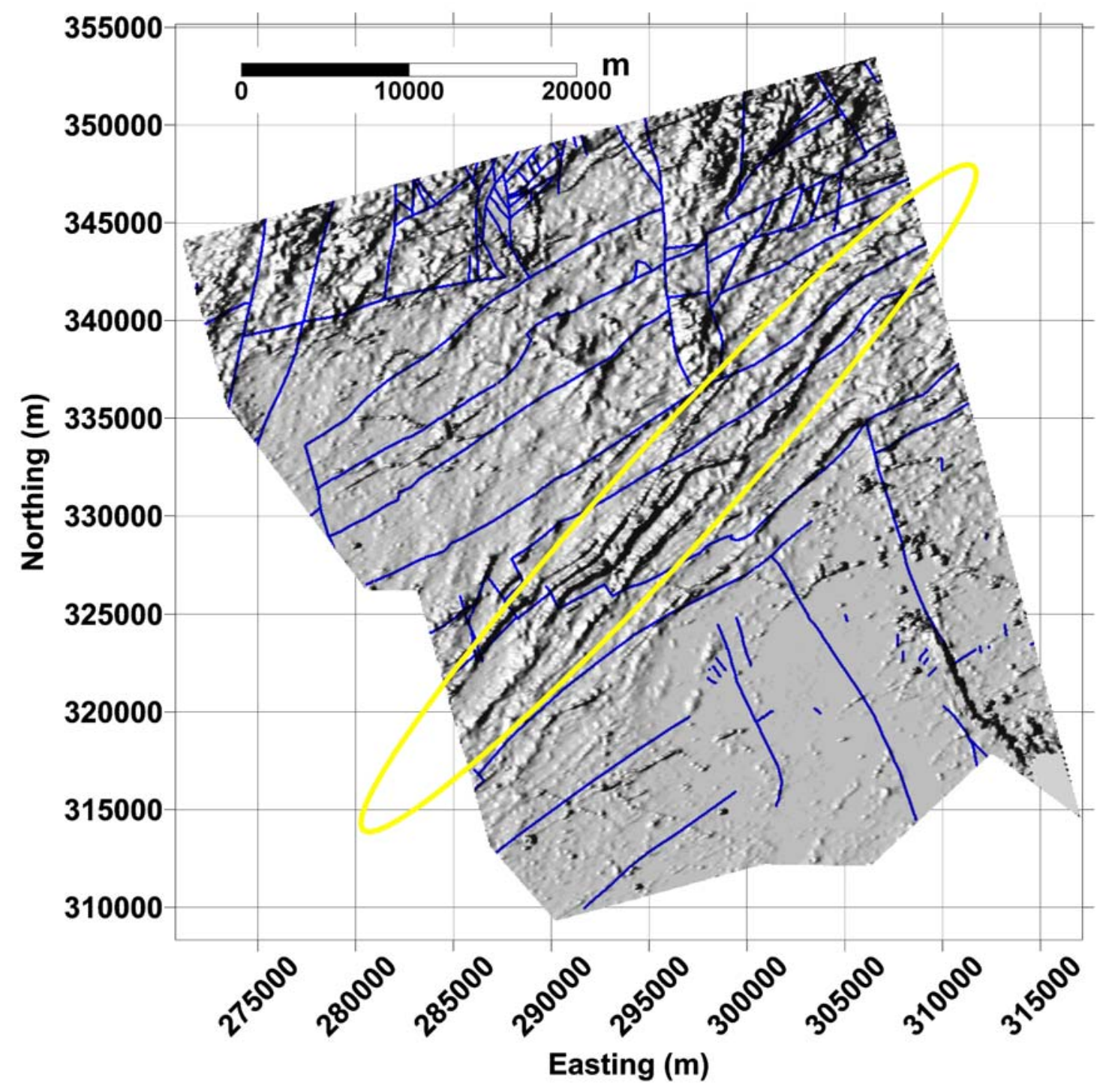

Figure 11 


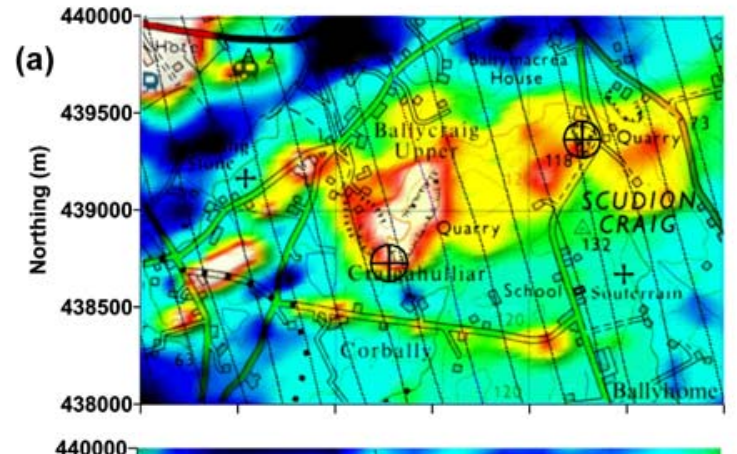

(b)

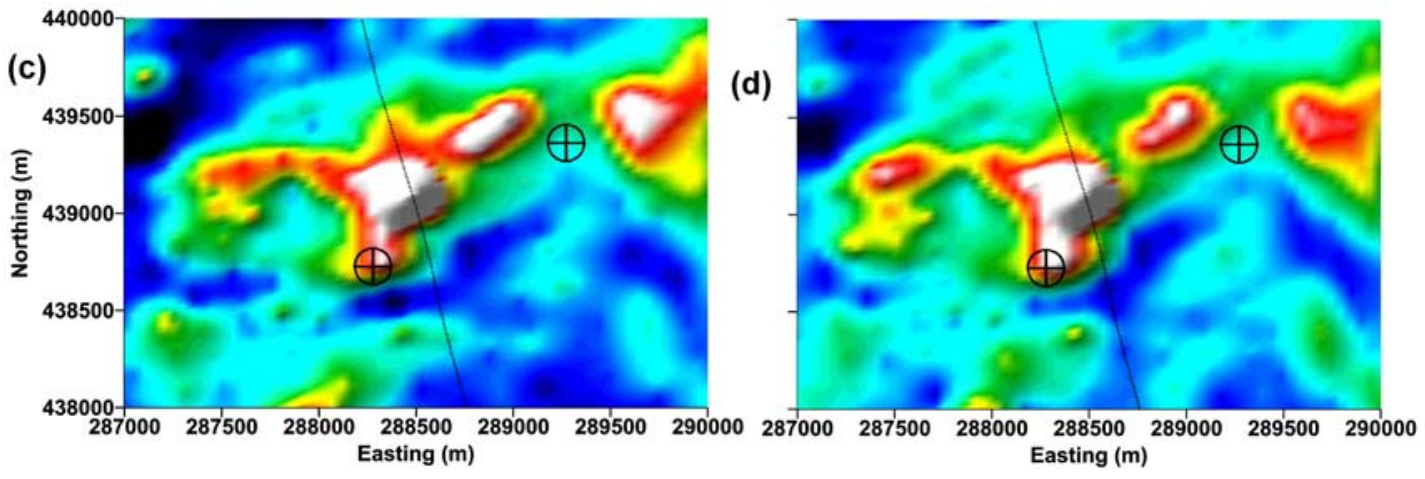

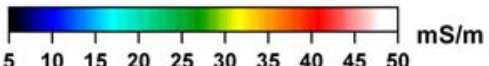

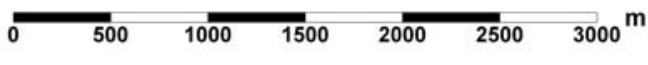

Figure 12
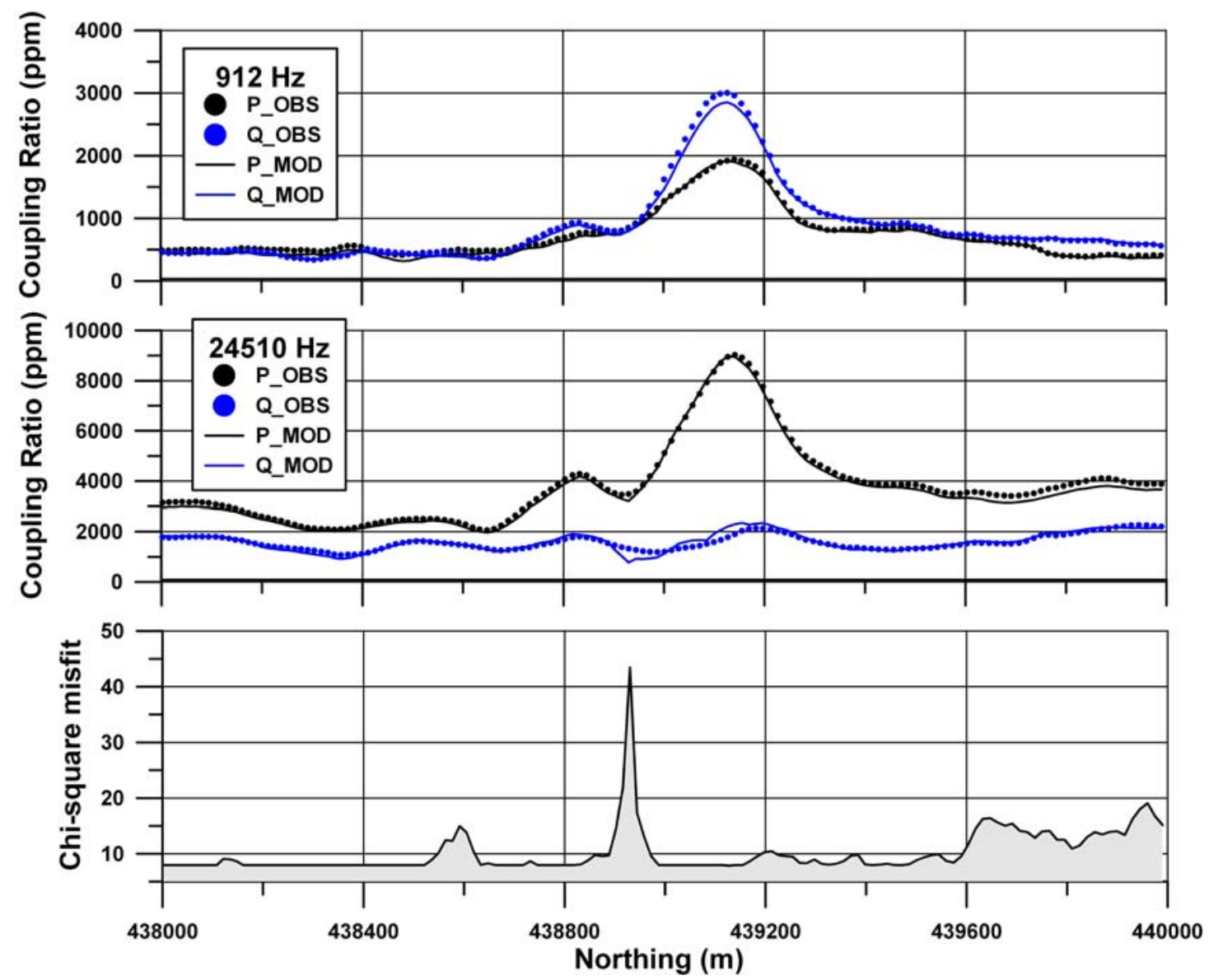

Figure 13 

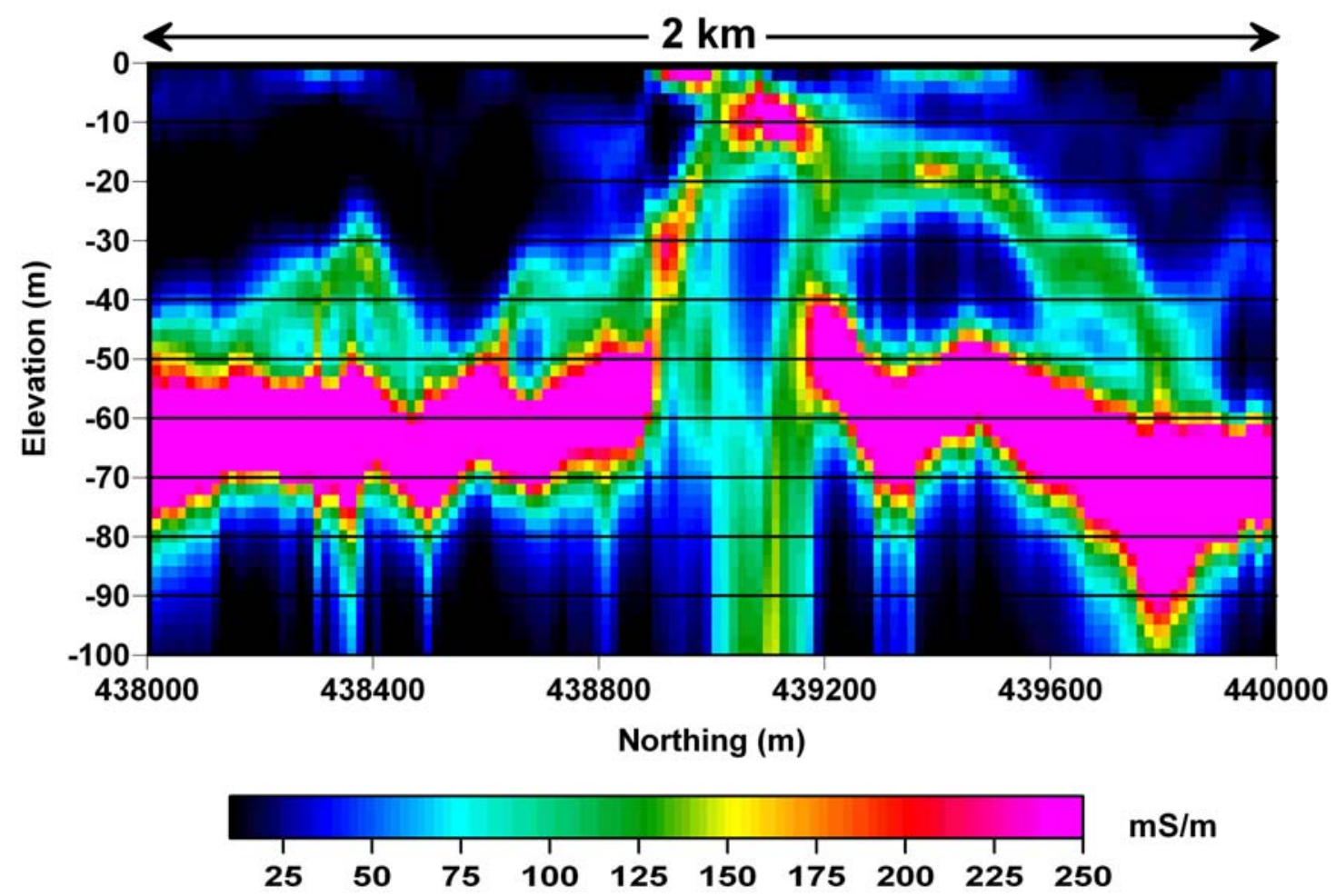

Figure 14 